\title{
Research on the Standardization of Talent Cultivation for Clinical Medical Degree Postgraduates Based on the Model of Two-Track Integration
}

\author{
Jihua Wei', Chenyi Zhuo', Chongchan Bao ${ }^{2}$, Qianli Tang2*, Shi Feng'2, \\ Lifang Huang ${ }^{3}$, Yan $\mathrm{Xu}^{3}$, Xueling Wang ${ }^{3}$ \\ ${ }^{1}$ The Affiliated Hospital of Youjiang Medical University for Nationality, Baise, China \\ ${ }^{2}$ Youjiang Medical University for Nationality, Baise, China \\ ${ }^{3}$ Guangxi University of Chinese Medicine, Nanning, China \\ Email: *htmgx@163.com
}

How to cite this paper: Wei, J. H., Zhuo, C. Y., Bao, C. C., Tang, Q. L., Feng, S., Huang, L. F., Xu, Y., \& Wang, X. L. (2019). Research on the Standardization of Talent Cultivation for Clinical Medical Degree Postgraduates Based on the Model of Two-Track Integration. Creative Education, 10, 3293-3298.

https://doi.org/10.4236/ce.2019.1013252

Received: October 29, 2019

Accepted: December 6, 2019

Published: December 9, 2019

Copyright $\odot 2019$ by author(s) and Scientific Research Publishing Inc. This work is licensed under the Creative Commons Attribution International License (CC BY 4.0).

http://creativecommons.org/licenses/by/4.0/

\begin{abstract}
At present, the training mode of clinical medical talents in China is mainly the combination of the standardized training of resident doctors and the postgraduate training of clinical medicine, which is the "double-track integration" talent training mode. The new model has created a group of graduate students with deep clinical thinking and strong clinical operation ability. However, due to the pressure of the situation, this group of students generally attaches importance to clinical research rather than scientific research. Thus, their scientific research ability is poor or even obviously insufficient, and their artificial spirit is weakened. The purpose of this article is to provide some suggestions and references for workers in the medical profession by comprehensively analyzing the advantages and disadvantages of this model and proposing some solutions.
\end{abstract}

\section{Keywords}

Double Track Integration, Clinical Medicine Specialty Type Graduate Student, Standardized Training for Residents

\section{Background of the "Double Track Integration" Mode}

In 2014, the "Opinions on deepening the training reform of clinical medical talents in collaboration with medical education" issued by the Ministry of Education clearly stated that the newly recruited professional graduate students in 
2015 not only need to complete postgraduate studies, but also participate in the standardized training of residents as a student, the so-called "dual-track integration" model. The training methods for all clinical medical professional postgraduates from 2015 must be carried out in accordance with the national standardized training requirements for residents. Students who meet the requirements of the training unit and complete the school on time can be granted a qualification certificate for the doctor, a standardized training certificate for the resident, a master's diploma and degree certificate. The "double track integration" model has brought about a breakthrough in medical education reform (Han, 2016).

\section{The Advantage of the "Double Track Integration" Model}

\subsection{Limitations of Traditional Training Models}

Because the training of clinical medical professional postgraduates and the standardized training of residents are different, that is, the former belongs to the pedagogy system, while the latter is the scope of hygiene. Based on this, there must be differences in the implementation of the two. Due to the lack of practical experience, the traditional professional postgraduate training has been in the exploratory stage, and the training model is similar to the academic one, that is, focusing on scientific research. After completing the basic knowledge, the professional postgraduate students are engaged in academic research and scientific research training, leading to their poor clinical thinking and ability.

China's "Practicing physician's Law" stipulates that: China adopts the doctor qualification examination system and the doctor practice registration system, and doctors who have not obtained the qualification certificate of professional doctors are not allowed to engage in medical activities alone. This regulation has led to the result that traditional professional graduate students have to engage in medical activities independently, which not only caused a great waste of medical resources, but also delayed the development of medical care in China (Zhao, 2017). The limitations of the traditional training model urgently require the emergence of a new system to resolve the contradiction between "regulation and training" and graduate education.

\subsection{The Advance of the "Double Track Integration" Model}

The "double track integration" model has effectively solved the contradiction between the standardized training of residents and the training of professional masters. Because of the similarity between the training objectives, methods and tasks of the two, the "two-track integration" model, which combines the two, allows the previous six-year task to be completed three years ahead of schedule, effectively saving money, reducing the length of training, optimizing resource allocation (Zhu, Zeng, \& Peng, 2018).

The "double track integration" model has greatly enhanced the clinical thinking and practice ability of professional graduate students. The clinical department rotation including internal medicine, surgery, pediatrics, obstetrics and 
gynecology, and emergency department not only broadens the students' knowledge reserve, clinical thinking and horizon, but also strengthens the surgical operation practice ability. More importantly, the students learn deeply what they have learned.

The "two-track integration" model has not only expanded the clinical ability of students, but also strengthened the training of scientific research capabilities. The combination of the two makes the scientific research subject more clinical, which is conducive to the expansion of knowledge reserves and the accumulation of experience (Ju \& Guan, 2016).

\section{Insufficient “Double Track Integration” Model}

\subsection{A Situation of Paying More Attention to Clinical and Ignoring Scientific Research}

In order to ensure that students can complete the standardized training tasks for residents on schedule, some colleges and universities have changed situation that the graduate students have completed the research and writing of the thesis for half a year before the appearance of the "double track integration" model, and adopted the model of clinical department rotation after entering the school. Students can only use after-school time and night to complete the mentor's projects and research tasks. This not only led to the decline in the quality of the completion of the project, but also significantly delayed the improvement of students' scientific research ability, so that they could not successfully complete the dissertation and study which affects the graduation (Tang, Guo, Pang et al., 2016).

\subsection{Increased Student Pressure}

Before the emergence of the "two-track integration" model, professional graduate students had half a year to learn basic theoretical knowledge, nearly half a year to complete scientific research tasks, and the remaining two years for department rotation. After the emergence of "Double Track Integration", in order to ensure the 33-month department rotation task, students only have about one month to carry out theoretical study and research, so that students universally undergo great pressure.

\subsection{Imperfect Department Rotation System}

Since the "two-track integration" reform is carried out in a pilot across the country, there is a lack of a unified department rotation system standard (He, Duan, Wu, \& Zhang, 2018). In addition, because the department teacher responsible for teaching has not received professional training, the understanding of the meaning of department rotation is not enough, and the teaching experience is insufficient, resulting in uneven quality of teaching and mostly different management system.

\subsection{Lack of Humanistic Education}

Because the students in the "double track integration" model spend most of their 
time in clinical department rotation, the time for scientific research and paper writing is compressed, and the time for humanistic education is greatly reduced.

\section{Solutions}

\subsection{Continue to Strengthen Clinical Thinking and Skills Training, and Gradually Increase the Proportion of Scientific Research}

After the admission of graduate students, they will be registered in the standardized management system of the resident doctors, and then transferred to the centralized training of "regulation and training" bases recognized by the country. Use the method of early admission, make full use of the one-month time for theoretical lectures, and work with academic graduate students for 3 months. Besides, focus on the use of trivial spare time, weekends for academic counseling and theoretical lectures. Open research laboratories, and encourage students to participate in academic creation and scientific research in various ways $(\mathrm{Wu}$, Zhang, \& Sun, 2018), such as appropriate increase of research funding, increase of academic creation evaluation, establishment of special scholarships to encourage scientific research, open research laboratories and improve request on research of graduates (Mo et al., 2016). While continuing to strengthen clinical thinking and ability, through a variety of ways to improve students' scientific research, gradually increase the proportion of scientific research. In the process of cultivating, it is important to pay attention to several abilities as follows. Firstly, cultivating literature review capabilities. In the age of informationization, how to quickly retrieve accurate and authentic documents is essential. When a graduate student is at school, the literature search should be included in the course and assessed strictly. Secondly, the ability to think independently. Clinical research capabilities require solid theoretical knowledge and certain clinical experience. On this basis, based on the characteristics of clinical cases, independent thinking, breaking through doubts, and forming the doubts and difficulties broken through to words. The writing of dissertations not only reflects the clinical ability and text application ability of graduate students, but also reflects the innovation ability. Thirdly, cultivating research and experimental capabilities. The ability of scientific research experiments is also a key factor in the cultivation of scientific research capabilities. While practicing in clinical practice, graduate students also need to follow the tutor or the brothers and sisters to conduct experimental operation and improve their research ability.

\subsection{Use Appropriate Methods to Ease Student Stress}

Set up a special psychological counseling team to regularly observe changes in students' psychological stress and ease their stress. Develop students' interest in the profession to recognize their strengths and weaknesses.

\subsection{Strengthen Medical Humanities Education}

Use the idea of evidence-based medicine, through the study of relevant cases, to 
improve the humanities quality of students.

\subsection{Establish an Excellent Faculty Team and Optimize the Department Rotation System}

A key part of improving the quality of teaching is excellent faculty. It also needs to continuously improve teaching methods and innovative teaching models (Tang et al., 2017). As a student, the first link to knowledge is the mentor (Liu, 2016). By encouraging further studies, an independent training course was set up to select outstanding mentors. We will deepen and improve the management system corresponding to the "mentor-student-hospital", and focus on the rigorous training of the teaching secretary and teaching teacher of the department (teaching and research office), focusing on the department rotation system and deepening the management concept. Regularly update and optimize the rotation system to make the rigid system alive. Appropriately raise the "regulation and training" salary of professional degree master students, and try to achieve equal pay for equal work with other ordinary "regulatory" students.

\section{Outlook}

The training of clinical medical professional postgraduates should not be equated only with the standardized training of resident doctors. It should also strive to coordinate the relationship between "regulation and training" and scientific research, and make full use of its initiative and creativity without affecting the "regulation and training". Grasp the trend of the times, and strive to complete the transformation from traditional single medical talents to research-oriented medical talents, and promote the development of China's medical and health undertakings. The "two-track integration" model is still in constant exploration. This is not only a personal matter, but also the participation of society and government.

\section{Founding}

Guangxi degree and postgraduate education reform project in 2019: Research on the standardization of talent cultivation for clinical medical degree postgraduates based on the model of two-track (No: JGY2019161). Guangxi Medical High-level Leading Talents Training “139” Project, Special Funding for Guangxi Special Experts.

\section{Conflicts of Interest}

The authors declare no conflicts of interest regarding the publication of this paper.

\section{References}

Han, Y. (2016). Discussion on the "Double track Integration" Training Model for Graduate Students Majoring in Clinical Medicine. Education for Chinese After-School, 27, 26-27. 
He, Y. F., Duan, C. Z., Wu, J., \& Zhang, S. Q. (2018). Study on the Problems and Countermeasures of Clinical Ability Training for Clinical Graduate Students. Medicine and Philosophy(B), 39, 90-92.

Ju, X. H., \& Guan, Y. J. (2016). Practice of "Four-in-One" Clinical Medicine Master Degree Training. China Higher Medical Education, 5, 124-125.

Liu, W. H. (2016). Current Situation and Prospect of the "Double Track Integration" Talent Training Model for Graduate Students and Resident Physicians in Clinical Medicine. Medical Education Management, 2, 535-538.

Mo, X. Q., Tao, L. H., Tang, Q. L., Zhou, Z. W., Wang, L. Y., \& Huang, L. (2016). Study on the Cultivation of Scientific Research Ability of Clinical Medical Degree under the “Double Track Integration” Model. China Medical Education Technology, 30, 13-14.

Tang, Q. L., Guo, M., Pang, G. F. et al. (2016). Problems and Countermeasures of Postgraduate Education in Clinical Medicine under the Joint-Track Model. Guangxi Education, 1, 49-50.

Tang, Q. L., Wang, S., Xie, D. D., Mo, X. Q., Huang, X. S., Huang, H. G., Li, J. H., \& Zeng, H. M. (2017). Application and Exploration of WPBL Teaching Model in Surgery Teaching. Creative Education, 8, 650-656. https://doi.org/10.4236/ce.2017.84049

Wu, P. L., Zhang, S. S., \& Sun, J. (2018). The Practice and Exploration of Medical Professional Quality Improvement of Medical Professional Postgraduates under the Model of “Double Track Integration”. Medical Education Research and Practice, 26, 804-807.

Zhao, Y. X. (2017). Rethinking the "Double Track Integration" Training Model for Master of Medical Degrees. Continuing Medical Education, 31, 52-53.

Zhu, H. Q., Zeng, C. C., \& Peng, X. Y. (2018). Thinking on the Training Model of Clinical Specialization Based on “Two-Track Integration”. Journal of Traditional Chinese Medicine Management, 26, 35-37. 